\title{
Total phenols, flavonoids, anthocyanins, ascorbic acid contents and antioxidant activity of Rhamnus kurdica Boiss for flower and leaves in flowering and pre- flowering stages
}

\author{
Mohammad Bagher Gholivand* and Marzieh Piryaei \\ Faculty of Chemistry, Razi University, Kermanshah, Iran.
}

Accepted 7 August, 2013

\begin{abstract}
The antioxidant capability, total phenol, total flavonoid, anthocyanins, ascorbic acid contents, and reducing power contents of polar and non-polar extracts for flower and leaves in two stages of growth for Rhamnus kurdica Boiss in flowering were evaluated in this work. The polar extraction of flower of $R$. kurdica Boiss had a higher total phenolic content as well as antioxidant activity compared to that of the other subfractions of flower and leaves in the different stages. Antioxidant activities of the samples were determined by three various testing systems namely 2, 2-diphenyl-1-picrylhydrazyl (DPPH), bcarotene/linoleic acid and reducing power assay. In DPPH system, the highest radical scavenging activity was seen by the polar subfraction in flowers of methanol extract $[21.04 \pm 1.35(\mu \mathrm{g} / \mathrm{ml})]$. Our findings demonstrate that the methanolic extracts of $R$. kurdica Boiss may be suggested as a new potential source of natural antioxidant.
\end{abstract}

Key word: Rhamnus kurdica Boiss, antioxidant, total phenolics, flavonoid, anthocyanins.

\section{INTRODUCTION}

Antioxidant activity is essential for life, to counteract the strongly oxidizing environment in which we live (Velioglu et al., 1998). Free radical formation is controlled naturally by compounds known as antioxidants. The damage in biological systems can be cumulative when the concentration of radical species and antioxidants are not in balance (Erkan et al., 2011). Phenolic compounds such as flavonoids, phenolic acids, diterpenes, and tannins have received attention for their high antioxidative activity (Rice-Evans et al., 1996).

Converging evidence from both experimental and epidemiological studies have demon-strated that cereals, vegetables, and fruits contain a myriad of phenolic compounds (Maheshwari et al., 2011). Natural anti- oxidants are compounds that increase the lifetime period and the nutrition value of food. They are transferred to beverages during the production process from different parts of plants (leaves, fruits, etc). Their beneficial effect on the health of consumers is seen mainly in reducing the concentration of free radicals and in decreasing hypertension (Theodoridis et al., 2011).

To the best of our knowledge, there is no information on the antioxidant properties of $R$. kurdica Boiss. The aim of this work was to evaluate the in vitro antioxidant properties of the methanol extracts of $R$. kurdica Boiss for flowers and leaves in two stages by DPPH, $\beta$ carotene/linoleic acid, reducing power assays, total phenolics, anthocyanins. 


\section{MATERIALS AND METHODS}

\section{Plant material}

The aerial parts of $R$. kurdica Boiss in different stage were gathered before flowering (pre-flowering) and flowering period in summer 2011 in the west of Iran. The aerial parts (leaves and flowers) were dried in shade (at room temperature). The plants were identified and authenticated by the Laboratory of Botanic Ecology of the Razi University. A voucher specimen was deposited at the chemistry herbarium of this laboratory under the code 2010 RKB.

\section{Chemicals}

Linoleic acid, 2, 6-di-tert-butyl-4-methylphenol (butylated hydroxytoluene, BHT), 2,2-diphenyl-1-picrylhydrazyl (DPPH, 95\%), gallic acid, oxalic acid, ascorbic acid (AA), catechin, PVPP (polyvinylpolypyrrolidone), cyanidin-3-glucoside and $\beta$-carotene, were procured from Sigma-Aldrich Chemie (Steinheim, Germany). Analytical grade methanol, and HPLC grade chloroform, standard Folin-Ciocalteu's phenol reagent, anhydrous sodium sulphate, ferric chloride, sodium carbonate, potassium ferricyanide, phosphate buffer solution (PBS), and Tween 40 were obtained from Merck (Darmstadt, Germany).

\section{Preparation of the methanol extract}

$60 \mathrm{~g}$ of the dried leaves in different stage of growth and 20 of powdered flower of $R$. kurdica Boiss were extracted with methanol by using Soxhlet apparatus at $50^{\circ} \mathrm{C}$ for $18 \mathrm{~h}$. The extract was filtered and concentrated under vacuum at $60^{\circ} \mathrm{C}$ by using a rotary evaporator (Heidolph, Laborota 4000, Schwabach, Germany), yielding a waxy material for leaves in per-flowering, leaves in flowering and flower were $(3.73 \mathrm{~g}, 6.25 \%),(4.16 \mathrm{~g}, 6.93 \% \mathrm{w} / \mathrm{w})$, and $(1.08 \mathrm{~g}, 5.40 \%)$ respectively. These extracts were suspended in water and extracted with chloroform $(4 \times 100 \mathrm{ml})$ to obtain $2.11 \mathrm{~g}$ (3.51\%), $2.97 \mathrm{~g}(4.95 \%)$, and $0.61 \mathrm{~g}(3.05 \%)$ polar and $1.22 \mathrm{~g}$ (2.03\%), $1.04(1.73 \%)$, and $0.38 \mathrm{~g}(1.9 \%)$ non-polar extracts. The extracts were stored in darkness at $4^{\circ} \mathrm{C}$ until used within a maximum period of one week.

\section{Antioxidant properties}

\section{1, 1-Diphenyl-2-picrylhydrazyl radical (DPPH) scavenging activity}

The free radical-scavenging activities of extract were measured by using 2, 2-diphenyl-1-picryl-hydrazyl (DPPH) as described by Sharififar et al. (2007) with some modification. $3 \mathrm{ml}$ of various concentrations of the extract was added to $1 \mathrm{ml}$ of a $0.5 \mathrm{mM}$ methanol solution of DPPH. The mixture was strongly shaken and left to stand at room temperature for $60 \mathrm{~min}$ in the dark. Then, the absorbance was measured at $517 \mathrm{~nm}$ against a blank. Determinations were made on a Shimadzu UV-visible spectrophotometer; model UV $160 \cup$ (Japan). Inhibition of free radical, DPPH, in percent (I \%) was calculated according to the formula:

$1 \%=\left(\left(A_{b}-A_{s}\right) / A_{b}\right) \times 100$

Where, $A_{b}$ is the absorbance of the control reaction (containing all reagents except the test compound), and As is the absorbance of the test compound.

The sample concentration providing $50 \%$ inhibition $\left(\mathrm{IC}_{50}\right)$ was calculated from the graph of inhibition percentage against sample concentration. Tests were carried out in triplicate. Ascorbic acid (AA) was used as positive control.

\section{$\beta$-Carotene linoleic acid assay}

The antioxidant activity was evaluated according to the method described by Miller (1971) with some modifications. Briefly, $1.5 \mathrm{ml}$ of $\beta$-carotene solution ( $1 \mathrm{mg} / \mathrm{ml}$ in chloroform), $3 \mathrm{ml}$ of linoleic acid solution $(10 \mathrm{mg} / \mathrm{ml}$ in chloroform), and $1.0 \mathrm{ml}$ of Tween 40 solution (300 $\mathrm{mg} / \mathrm{ml}$ in chloroform) were pipetted into a $250 \mathrm{ml}$ flask. The chloroform was removed by rotary vacuum evaporator, and $150 \mathrm{ml}$ deionized water was added to the residue and the mixture was shaken to form an emulsion. Three hundred and fifty microliter (350 $\mu \mathrm{l})$ of test sample in methanol $(2 \mathrm{mg} / \mathrm{ml})$ was mixed with $2.5 \mathrm{ml}$ of this reagent, and the emulsion system was incubated for up to $24 \mathrm{~h}$ at room temperature. The same procedure was repeated with the synthetic antioxidant, BHT as positive control, and a blank containing only $350 \mu \mathrm{l}$ of methanol. After this incubation period, absorbances of the mixtures were measured at $490 \mathrm{~nm}$. Antioxidative capacities of the extract were compared with those of $\mathrm{BHT}$ and blank.

\section{Reducing power}

The reducing power of extract was determined according to the method of Sfahlan et al. (2009) with some modifications. Different concentrations of methanolic extract (polar and nonpolar) of plant in methanol $(1.0 \mathrm{ml})$ were mixed with $2.5 \mathrm{ml}$ of phosphate buffer $(200$ $\mathrm{mM}, \mathrm{pH} 6.6)$ and $2.5 \mathrm{ml}$ of $1 \%$ potassium ferricyanide. The mixture was incubated at $50^{\circ} \mathrm{C}$ for $20 \mathrm{~min}$. A portion $(2.5 \mathrm{ml})$ of trichloroacetic acid (10\%) was added to the mixture to stop the reaction, which was then centrifuged at $3000 \mathrm{~g}$ for $10 \mathrm{~min}$. The upper layer of solution $(2.5 \mathrm{ml})$ was mixed with distilled water $(2.5$ $\mathrm{ml})$ and $\mathrm{FeCl}_{3}(0.5 \mathrm{ml}, 0.1 \%)$, and the absorbance was measured at $700 \mathrm{~nm}$ : higher absorbance indicates higher reducing power. Ascorbic acid was used as positive control.

\section{Determination of total phenolic contents}

Total phenolic contents of the extract and the oil were determined using the Folin-Ciocalteu reagent according to the method of Singleton and Rossi (1965) using gallic acid as standard, with some modifications. The extract solution $(0.1 \mathrm{ml})$ containing $1000 \mu \mathrm{g}$ of the extract was mixed with $46 \mathrm{ml}$ of distilled water in a volumetric flask and $1 \mathrm{ml}$ Folin-Ciocalteu reagent was added, and the flask was thoroughly shaken. The mixture was allowed to react for $3 \mathrm{~min}$ and $3 \mathrm{ml}$ aqueous solution of $2 \% \mathrm{Na}_{2} \mathrm{CO}_{3}$ was added. At the end of incubation of $2 \mathrm{~h}$ at room temperature, absorbance of each mixture was measured at $760 \mathrm{~nm}$. The same procedure was also applied to the standard solutions of gallic acid, and a standard curve was obtained. Total phenol contents were expressed as $\mu \mathrm{g}$ gallic acid equivalents per $\mathrm{mg}$ of the extract. All tests were carried out in triplicate, and gallic acid equivalent values were reported as $X \pm S D$ of triplicates.

\section{Determination of total flavonoids}

A modified protocol of that described by Kim et al. (2003) was employed. A $0.1 \mathrm{ml}$ aliquot of methanolic extract, appropriately diluted, was mixed with $0.4 \mathrm{ml}$ distilled water in a $1.5 \mathrm{~mL}$ microcentrifuge tube, $0.03 \mathrm{ml}$ of $5 \% \mathrm{NaNO}_{2}$ was added and the mixture was allowed to react for $5 \mathrm{~min}$. Following this, $0.03 \mathrm{ml}$ of $10 \% \mathrm{AlCl}_{3}$ was added and the mixture stood for a further $5 \mathrm{~min}$. Finally, the reaction mixture was treated with $0.2 \mathrm{ml}$ of $1 \mathrm{M} \mathrm{Na}_{2} \mathrm{CO}_{3}$ and $0.24 \mathrm{ml}$ distilled water, and the absorbance at $510 \mathrm{~nm}$ was obtained against a blank prepared similarly, by replacing extract with distilled water. Total flavonoid content was calculated from a calibration curve using catechin as standard, and expressed as mg catechin equivalents (CTE) per $100 \mathrm{~g}$ plant (Dourtoglou et al., 
Table 1. Antioxidant activities and total phenol of Rhamnus kurdica Boiss methanol extract in two stage of growth for leaves and flowers.

\begin{tabular}{lccc}
\hline Sample & DPPH IC $_{\mathbf{5 0}}(\boldsymbol{\mu} \mathbf{g} / \mathbf{m l})$ & $\boldsymbol{\beta}_{\text {-Carotene bleaching }}(\mathrm{RAA})(\%)$ & Total phenol contents $(\boldsymbol{\mu} \mathbf{g} / \mathbf{m g})$ \\
\hline Polar subfraction $^{\mathrm{L}-\mathrm{P}}$ & $47.16 \pm 3.83$ & $78.84 \pm 1.96$ & $212.72 \pm 8.82$ \\
Nonpolar subfraction $^{\mathrm{L}-\mathrm{P}}$ & $321.49 \pm 9.61$ & $34.29 \pm 1.43$ & $49.87 \pm 2.87$ \\
Polar subfraction $^{\mathrm{L}-\mathrm{F}}$ & $31.11 \pm 3.57$ & $98.06 \pm 3.98$ & $252.33 \pm 7.18$ \\
Nonpolar subfraction $^{\mathrm{L}-\mathrm{F}}$ & $287.02 \pm 7.47$ & $54.77 \pm 1.37$ & $76.30 \pm 3.47$ \\
Polar subfraction $^{F}$ & $21.04 \pm 1.35$ & $99.13 \pm 3.12$ & $307.38 \pm 10.34$ \\
Nonpolar subfraction $^{\mathrm{F}}$ & $98.36 \pm 4.02$ & $61.39 \pm 0.67$ & $102.51 \pm 4.21$ \\
BHT $^{\text {Ascorbic acid }}$ & $19.5 \pm 1.06$ & 100 & $\mathrm{nd}$ \\
Ascon & $5.1 \pm 0.87$ & $\mathrm{nd}$ & $\mathrm{nd}$ \\
\hline
\end{tabular}

${ }^{\mathrm{L}-\mathrm{P}}$ Leaves in pre - flowering; ${ }^{\mathrm{L}-\mathrm{F}}$ leaves in flowering; ${ }^{\mathrm{F}}$ flower. $\mathrm{Nd}$, Not detected.

2006).

\section{Anthocyanins}

Total anthocyanin content was measured with the $\mathrm{pH}$ differential absorbance method, as described by Cheng and Breen (1991). Briefly, absorbance of the extracts were measured at 510 and 700 $\mathrm{nm}$ in buffers at $\mathrm{pH} 1.0$ (hydrochloric acid-potassium chloride, 0.2 M) and 4.5 (acetate acid- sodium acetate, $1 \mathrm{M}$ ). Anthocyanin content was calculated using a molar extinction coefficient of 29,600 (cyanidin-3- glucoside) and absorbance of

$A=\left[\left(A_{510}-A_{700}\right)_{p H ~ 1.0}-\left(A_{510}-A_{700}\right) p H 4.5\right]$

Results were expressed as $\mu \mathrm{g}$ cyanidin-3-glucoside equivalents $100 \mathrm{mg}^{-1} \mathrm{fw}$ (Pantelidis et al., 2007).

\section{Ascorbic acid content}

Ascorbic acid of the extracts was determined using ascorbic acid as standard, with some modifications. The samples $(1 \mathrm{~g})$ and $4 \mathrm{ml}$ oxalic acid (1\%) were mixed, homogenised for $1 \mathrm{~min}$, and filtered. Polyvinylpolypyrrolidone (PVPP) $(100 \mathrm{~g})$ was added to $2.5 \mathrm{ml}$ of the filtered sample, to remove phenols, and 2-3 drops of $\mathrm{H}_{2} \mathrm{SO}_{4}(25 \%)$ were added, to reduce the $\mathrm{pH}$ to below 1 . Absorbance of the mixture was determined at $254 \mathrm{~nm}$. Results were expressed as $\mathrm{mg}$ ascorbic acid (AA) $100 \mathrm{~g}^{-1}$ fresh weight (fw) (Pantelidis et al., 2007).

\section{RESULTS AND DISCUSSION}

\section{Antioxidant properties}

\section{Free radical-scavenging activity}

The free radical-scavenging abilities of the methanol extract of $R$. kurdica Boiss and polar and nonpolar fractions (water, chloroform) against DPPH were tested, and the results are presented in Table 1. The polar subfraction for flower of methanol extract provided the highest radical-scavenging activity with the lowest $\mathrm{IC}_{50}$ value of $21.04 \pm 0.35 \mu \mathrm{g} / \mathrm{ml}$ than the other subfractions. The antioxidant activities of the plant extract was also evaluated by the spectrophotometric $\beta$-carotene bleaching test. The rate of $\beta$-carotene bleaching can be slowed down in the presence of antioxidants (Kulisic et al., 2004). The relative antioxidative activities (RAAs) of the extracts were calculated from the equation, RAA = A sample/A BHT, where A BHT is the absorbance of the control (BHT) and A sample is the absorbance of the extract. The calculated RAAs of the extract are given in Table 1. In the reducing power assay, the presence of antioxidants in the sample would result in the reducing of $\mathrm{Fe}^{3+}-\mathrm{Fe}^{2+}$ by donating an electron. Amount of $\mathrm{Fe}^{2+}$ complex can then be monitored by measuring the formation of Perl's Prussian blue $\mathrm{Fe}^{4+}[\mathrm{Fe}(\mathrm{CN}) 6]^{3+}$ at 700 $\mathrm{nm}$. Increasing absorbance at $700 \mathrm{~nm}$ indicates an increase in reductive ability. Figure $1 a, b, c$ shows the reducing power of the methanolic (polar and non-polar) extract of $R$. kurdica Boiss as a function of their concentrations. The amounts of total phenolics in the extract for different stage were determined spectrometrically according to the Folin-Ciocalteu procedure and calculated as gallic acid equivalents. Gallic acid is a water-soluble polyhydroxyphenolic compound that can be found in various natural plants. The standard curve equation was, y (absorbance) = $0.0003 \times$ gallic acid $(\mu \mathrm{g})+0.00534$. The amounts of total phenols found in the plant methanolic extract are shown in Table 1.

\section{Flavonoid}

The standard curve equation for determination flavonoids with catechin is y (absorbance) $=0.004 \times$ catechin $(\mu \mathrm{g})+$ 0.0483 . The amounts of total flavonoids found in plant methanolic extract for flowers of $R$. kurdica Boiss was $101.17 \pm 5.74 \mu \mathrm{g} / \mathrm{mg}$, for leaves in flowering stage was $86.32 \pm 2.98 \mu \mathrm{g} / \mathrm{mg}$ and in pre-flowering stage for leaves was $51.67 \pm 1.54 \mu \mathrm{g} / \mathrm{mg}$.

\section{Anthocyanins}

Significant differences in anthocyanin content were 
Table 2. Flavonoid, anthocyanins and ascorbic acid contents of R.kurdica Boiss methanol extract in two stages of growth for leaves and flowers.

\begin{tabular}{|c|c|c|c|}
\hline Sample & Flavonoid $\mu \mathrm{g} / \mathrm{mg}$ & Anthocyanin $\left(\mu \mathrm{g} 100 \mathrm{mg}^{-1} \mathrm{fw}\right)$ & Ascorbic acid ( $\left.\mu \mathrm{g} 100 \mathrm{mg}^{-1} \mathrm{fw}\right)$ \\
\hline Flower & $101.17 \pm 5.74$ & $21.53 \pm 0.57$ & $25.13 \pm 1.59$ \\
\hline Leaves in flowering & $86.32 \pm 2.98$ & $12.36 \pm 0.84$ & $16.87 \pm 1.02$ \\
\hline Leaves in pre - flowering & $51.67 \pm 1.54$ & $2.27 \pm 0.03$ & $14.06 \pm 1.07$ \\
\hline
\end{tabular}
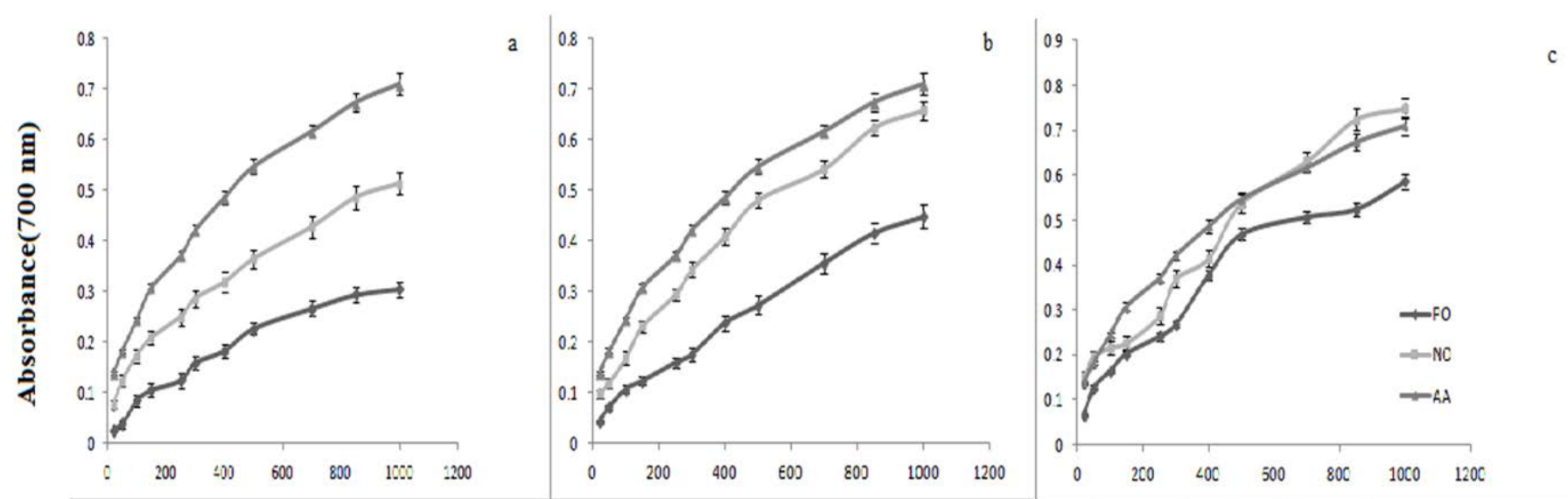

concentration $((\mu \mathrm{g} / \mathrm{mL})$

Figure 1. Reducing power of different concentrations of methanolic extract polar and non-polar subfraction. a: leaves in the preflowering stage, b: leaves in the flowering stage and c: flowers of Rhamnus kurdica Boiss compared to ascorbic acid, (spectrophotometric detection of the $\mathrm{Fe}^{+3}-\mathrm{Fe}^{+2}$ transformations). Polar (PO) and non-polar (NO) subfraction extract; $\mathrm{AA}$, ascorbic acid.

recorded, since these pigments are responsible for the red and blue color. The nonpolar subfraction in flowering stage contained the highest anthocyanin content expressed as cyanidin-3- glucoside. The results are shown in Table 2 . The results show relation between anthocyanins and antioxidant activity.

\section{Ascorbic acid}

Significant differences in ascorbic acid content among the different sub-fraction are recorded in Table 2. The flowers subfraction had the highest content of ascorbic acid $\left(25.13 \pm 1.59 \mathrm{mg} 100 \mathrm{~g}^{-1} \mathrm{fw}\right)$.

\section{REFERENCES}

Cheng GW, Breen PJ (1991). Activity of phenylalanine ammonialyase (PAL) and concentrations of anthocyanins and phenolics in developing strawberry fruit. J. Am. Soc. Horticult. Sci.116:865-869.

Dourtoglou VG, Mamalos A, Makris DP (2006). Storage of olives (Olea europaea) under $\mathrm{CO} 2$ atmosphere: Effect on anthocyanins, phenolics, sensory attributes and in vitro antioxidant properties Idolo Tedesco, Gian Luigi Russo, Filomena Nazzaro, Maria Russo, Rosanna Palumbo. Food Chem. 99:342-349.

Erkan N, Cetin H, Ayranci E (2011). Antioxidant activities of Sideritis congesta Davis et Huber-Morath and Sideritis arguta Boiss et Heldr:
Identification of free flavonoids and cinnamic acid derivatives. Food Res. Int. 44:297-303.

Kim DO, Chun OK, Kim YJ, Moon HY, Lee CY (2003). Quantification of polyphenolics and their antioxidant capacity in fresh plums. J. Agric. Food Chem. 516:509-6515.

Kulisic T, Radonic A, Katalinic V, Milos M (2004). Use of different methods for testing antioxidative activity of oregano essential oil. Food Chem. 85:633-640.

Maheshwari DT, Yogendra Kumar MS, Verma SK, Singh VK, Singh SN (2011). Antioxidant and hepatoprotective activities of phenolic rich fraction of Seabuckthorn (Hippophae rhamnoides L.) leaves. Food Chem. Toxicol. 49(9):2422-2428.

Miller HE (1971). A simplified method for the evaluation of antioxidants. J. Am. Oil Chem. Soc. 48:91-97.

Pantelidis GE, Vasilakakis M, Manganaris GA, Diamantidis Gr (2007). Antioxidant capacity, phenol, anthocyanin and ascorbic acid contents in raspberries, blackberries, red currants, gooseberries and Cornelian cherries. Food Chem. 102:777-783.

Rice-Evans CA, Miller NJ, Paganga G (1996). Structure-antioxidant activity relationships of flavonoids and phenolic acids. Free Rad. Biol. Med. 20:933-956.

Sfahlan J, Mahmoodzadeh A, Hasanzadeh A, Heidari A, Jamei R (2009). Antioxidants and antiradicals in almond hull and shell (Amygdalus communis L.) as a function of genotype. Food Chem. 115:529-533.

Sharififar F, Moshafi MH, Mansouri SH, Khodashenas M, Khoshnoodi M (2007). In vitro evaluation of antibacterial and antioxidant activities of the essential oil and methanol extract of endemic Zataria multiflora Boiss. Food Control. 18:800-805.

Singleton VL, Rossi JA (1965). Colorimetry of total phenolics with phosphomolybdic phosphotungstic acid reagents. Am. J. Enol. Viticul. 16:144-158. 
Theodoridis G, Las kov M, ker kov V, Tegou A, Giantsiou N, Jandera P (2006). Molecular imprinting of natural flavonoid antioxidants: Application in solid-phase extraction for the sample pretreatment of natural products prior to HPLC analysis. J. Sep. Sci. 29:2310-2321.
Velioglu YS, Mazza G, Gao YL, Oomah BD (1998). Antioxidant activity and total phenolics in selected fruits, vegetables and grain products. J. Agric. Food Chem. 46:4113-4117. 